Original Article

\title{
Walking Dynamic Similarity Induced by a Combination of Froude and Strouhal Dimensionless Numbers: Modela-w
}

\author{
Authors: \\ David Villeger ${ }^{\mathrm{a}}$, Antony Costes ${ }^{\mathrm{a}}$, Bruno Watier ${ }^{\mathrm{a}, \mathrm{b}}$ and Pierre Moretto ${ }^{\mathrm{a}}$
}

\section{Affiliation:}

${ }^{\text {a }}$ University of Toulouse, UPS, PRISSMH, 118 route de Narbonne, F-31062 Toulouse Cedex 9, France

${ }^{\mathrm{b}}$ University of Toulouse, CNRS ; LAAS ; 7 avenue du colonel Roche, F-31077 Toulouse, France

\section{Corresponding author:}

David Villeger

PRISSMH

Faculté des Science du Sport et du Mouvement Humain (F2SMH)

Université de Toulouse III, 118 route de Narbonne, F-31062 Toulouse Cedex 9, France.

Phone: +33 (0)6 51491158 / +33 (0)5 61556440

Fax: +33 (0)5 61558280

Email: david.villeger@univ-tlse3.fr

Word count (abstract): 176 words

Word count (Introduction through References with appendix): 2998 words

Number of figure: 3 figures

Number of table: 2 tables 


\title{
Walking Dynamic Similarity Induced by a Combination of Froude and Strouhal Dimensionless Numbers: Modela-w
}

\begin{abstract}
The aim of this study was to assess the accuracy of a new dimensionless number associating Froude (Nfr) and Strouhal (Str) called Modela-w to induce walking dynamic similarity among humans of different sizes. Nineteen subjects walked in three experimental conditions i) constant speed, ii) similar speed (Nfr) and iii) similar speed and similar step frequency (Modela-w). The dynamic similarity was evaluated from scale factors computed with anthropometric, temporal, kinematic and kinetic data and from the decrease of the variability of the parameters expressed in their dimensionless form. Over a total of 36 dynamic parameters, dynamic similarity from scale factors was met for 11 (mean $r=0.51$ ), 22 (mean $r=0.52$ ) and 30 (mean $r=0.69$ ) parameters in the first, the second and the third experimental conditions, respectively. Modela-w also reduced the variability of the dimensionless preceding parameters compared to the other experimental conditions. This study shows that the combination of Nfr and Str called Modela-w ensures dynamic similarity between different-sized subjects and allows scientists to impose similar experimental conditions removing all anthropometric effects.
\end{abstract}

Keywords: dynamic similarity; spring mass model; center of mass; similar speed; similar frequency. 


\section{Introduction}

Dynamic similarity studies allow for the comparison of the locomotion between species [1] and the reduction of different-sized subjects inter-individual variability [2,3]. The concept of dynamic similarity states that two systems are dynamically similar when all the lengths, the masses and the times of the smaller are equal to those of the taller by multiplying them with the same coefficients $C_{L}, C_{M}$ and $C_{T}$ which represent the basis scale factors. Therefore, all other mechanical scale factors are determined from the combination of the basis scale factor, such as speed, force or impulse (Table 1). The main challenge when studying locomotion in different-sized specimens is to define experimental conditions enabling dynamic similarity to be observed. Dynamic similarity between two systems is met in particular conditions, which depend on the nature of the force involved.

The Inverted Pendulum (IP) consists of a body mass represented at the Center of Mass (CoM) oscillating at the end of a massless rigid segment [4], and is mainly used to model walking because of the out-of-phase relationship between potential $\left(E_{P}=m g h\right.$; $\mathrm{m}$ the mass, $\mathrm{g}$ the gravity and $\mathrm{h}$ the CoM height $)$ and kinetic $\left(E_{K}=0.5 m v^{2} ; \mathrm{v}\right.$ the speed) energies. The ratio of $E_{K}$ and $E_{\mathrm{P}}$ can be simplified to Froude number $\left(N f r=2 E_{K} / E_{P}\right)$. Many studies consider Nfr as the normalized speed (dimensionless speed) and use it to compare different species [1] or subjects speeds reported to a characteristic length. Another use of Nfr is to first determine Nfr fractions, then walking speed adapted to body length [2,3]. These authors demonstrate that it is a good mean to establish dynamic similarity between different-sized subjects. Note that this method aims to impose a same Nfr fraction to the subject (i.e. a same energy ratio).

However, more recent studies have shown the limits in considering the walking gait as an IP $[5,6]$. These works suggested the presence of an elastic phenomenon in walking. Therefore, the Spring Mass Model (SMM) seems to be adapted [7]. SMM, taking into 
account an elastic component, Elastic Energy $\left(E_{E}=0.5 k \Delta l^{2}\right.$ with $\mathrm{k}$ for the spring stiffness and $\Delta \mathrm{l}$ for the variation of the spring length), could play an important role in mechanical energy conservation in walking as it has been shown to do in running [8].

The SMM is a conservative system: $E_{K}+E_{P}+E_{E}=$ constant. Besides the energy transfer that occurs at the CoM during running (Modela-r; [9]), in walking a transfer occurs from $E_{K}$ to $E_{P}$ and $E_{E}$ in the first half of stance, and then, conversely in the second half. Indeed, upon reaching the apex of $\mathrm{CoM}$ trajectory, ( $\mathrm{E}_{\mathrm{P}}$ increases) the spring is under compression ( $\mathrm{E}_{\mathrm{E}}$ increases) and the CoM speed is reduced ( $\mathrm{E}_{\mathrm{K}}$ decreases); then, the CoM returns to its initial height ( $E_{P}$ decreases), the spring length recovers its rest length $\left(E_{E}\right.$ decreases) and the CoM speed rises ( $\mathrm{E}_{\mathrm{K}}$ increases). We propose to develop the energy ratio as follows and to name it Modela-w:

Modela $-w=\frac{E_{K}}{E_{P}+E_{E}}=\left(\frac{m g h+(1 / 2) k \Delta l^{2}}{(1 / 2) m v^{2}}\right)^{-1}=\left(2 \frac{m g h}{m v^{2}}+\frac{k \Delta l^{2}}{m v^{2}}\right)^{-1}=\left(2 \frac{g h}{v^{2}}+\frac{f_{0}^{2} \Delta l^{2}}{v^{2}}\right)^{-1}$

with $f_{0}=\sqrt{k / m} ;\left(v^{2} / g h\right)$ is usually referred to as $\mathrm{Nfr}$.

As the authors $[1,2]$ suggested, given a concomitant use of $\mathrm{Nfr}$ and Strouhal $(\mathrm{Str}=$ frequency $\times$ length/velocity) to induce dynamic similarity in running which shares the same SMM with walking, Modela-w can be expressed in Nfr and Str terms:

$\frac{E_{K}}{E_{P}+E_{E}}=\left(2 \frac{g h}{v^{2}}+\frac{f_{0}^{2} \Delta l^{2}}{v^{2}}\right)^{-1}=\left(2 N f r^{-1}+S t r^{2}\right)^{-1}$

Thus, Modela-w reveals a combination of Nfr and Str: Modela- $w=1 /\left(2 N f r^{-1}+S t r^{2}\right)$ and is adapted to explain the energy transfer that occurs during walking if an elastic component is considered. 
Our study aims to ensure dynamic similarity among different-sized subjects using a combination of $\mathrm{Nfr}$ and Str for walking through the introduction of Modela-w as a dimensionless number issued from the energy transfer at the CoM. The main idea is to determine similar conditions for different-sized subjects inducing similar behaviors, and therefore the decrease of inter-subject variability of dimensionless parameters.

\section{Methods}

\subsection{Population}

Nineteen healthy men $(n=19)$ took part in this study after signing an informed consent document. They were chosen so as they had the same density index (mass / height ${ }^{3}$ ) to respect the proportionality law inducing the tallest as the heaviest and vice versa. Their characteristics were $($ mean $\pm \mathrm{sd}[\min ; \max ])$ : age $23 \pm 5[18 ; 36]$ years, height $1.79 \pm 0.07$ [1.68; 1.94] m, mass $80.7 \pm 11[64 ; 102.9] \mathrm{kg}$ and density index $14.01 \pm 0.42[13.27 ; 14.85]$ $\mathrm{kg} \cdot \mathrm{m}^{-3}$. All were familiarized with walking test performed on a treadmill. The CoM height $\left(\mathrm{l}_{\mathrm{i}}\right)$ was determined from the $\mathrm{i}^{\text {th }}$ subject's anatomic position $(i \in[1, n])$ with the anthropometric model of De Leva [10]. In order to assess leg joint angles, the center of rotation of the hip was determined using the SCoRE method [11].

\subsection{Experimentation}

\subsubsection{General procedure}

For three dimensional kinematic analysis, 42 reflective markers were fixed on subject bone landmarks $[12,13]$. They performed walking tests with speed and/or step frequency determined from Nfr and Str. To define the experimental conditions, Nfr and Str respectively equaled to $v^{2} / g l$ and to $f l / v$; with $g$ the gravity, $\mathrm{f}$ the frequency oscillation of the CoM, 1 the CoM height and $\mathrm{v}$ the forward speed. Experimentation was realized on a treadmill (PF 500 
CX, PRO FORM, Villepreux, FRANCE) mounted on a large forceplate sampled at $1 \mathrm{kHz}$ (AMTI, Watertown, MA, USA) in a space surrounded by twelve optoelectronic cameras sampled at $200 \mathrm{~Hz}$ (VICON, Oxford's metrics, Oxford, UK). After a familiarization period, the subjects had to perform three trials per walking test [14] that were repeated in different experimental settings.

\subsubsection{Experimental conditions (EC)}

The experimentation consisted of three steps detailed in Fig. 1 and below: i) same speed $\left(\mathrm{EC}_{\mathrm{SPEED}}\right)$, ii) similar speed (i.e. same Froude, $\left.\mathrm{EC}_{\mathrm{NFR}}\right)$ and iii) similar speed and similar frequency (i.e. same Nfr and same Str, then same Modela-w, $\mathrm{EC}_{\mathrm{MOD}}$ ).

$E C_{S P E E D}$

The subjects performed four walking stages with speeds set at $0.56,1.11,1.67$ and $2.22 \mathrm{~m} . \mathrm{s}^{-1}$ (Eq. 3) corresponding to increments of $0.556 \mathrm{~m} \cdot \mathrm{s}^{-1}\left(=2 \mathrm{~km} \cdot \mathrm{h}^{-1}\right)$. The procedure presented below was repeated for each speed stage. The first experimental condition consisted of setting the same speed for all subjects:

$v_{i}=$ constant $=v$

$E C_{N F R}$

The second experimentation step entailed imposing similar velocities. A mean $\overline{\mathrm{Nfr}}$ was computed from $\mathrm{EC}_{\mathrm{SET}}$. Then, similar velocities for each subject were determined from $\overline{\mathrm{Nfr}}$ (Eq. 4)

$\operatorname{vsim}_{i}=\sqrt{\overline{\overline{N f r} g l_{i}}}$ 
The third experimentation step consisted of imposing similar velocities (Eq. 4) and similar frequencies (induced by a metronome). A mean $\overline{\mathrm{Str}}$ was computed from $\mathrm{EC}_{\mathrm{NFR}}$. Then, similar frequencies for each subject were determined from $\overline{\operatorname{Str}}$ (Eq. 5)

$f \operatorname{sim}_{i}=\overline{\operatorname{Str}} \frac{v \operatorname{sim}_{i}}{l_{i}}$

\subsection{Parameters assessed}

$4^{\text {th }}$ order zero lag Butterworth filters were applied to kinematic and kinetic data with a cut off frequency set at $6 \mathrm{~Hz}$ and $10 \mathrm{~Hz}$ respectively [15]. Then, five consecutive cycles were averaged at each speed stage.

\section{Kinetic parameters}

The ground reaction forces (GRF) were measured by a large force platform under the treadmill. The double support phase was detected via the method of Verkerke et al. [16], and GRF during double support were decomposed from transition functions [17]. The kinetic parameters suggested by Delattre et al. [2] to study the GRF similarities during running were adapted to describe vertical forces during walking (Fig. 2). Eight parameters were studied aiming the reader comprehension of the results. The different parameters are presented in Fig. 2. From the vertical reaction force, the time of contact (TC), the damping peak force (DPF), the loading rate (LR) and the vertical impulse (VI) were computed. LR (in N.s $\mathrm{s}^{-1}$ ) corresponded to the gain of force between $10 \%$ and $90 \%$ of the first vertical peak divided by the time to reach this level. From the antero-posterior reaction force, we calculated the braking peak force (BPF), the time to propulsive peak force (TPPF), the braking impulse (BI) and the propulsion impulse (PI).

The mass (m), the CoM height (1) measured in standard anatomic position and the CoM oscillation frequency (f), were considered to compute the dimensionless values of the 
kinetic parameters and normalize them with respect to the basis dimensions $\left[\mathrm{M}, \mathrm{L}_{\text {and }} \mathrm{T}^{-1}\right]$ (see Table 1). A "D" has been added as an exponent of the parameter acronym to differentiate the dimensionless value from the real one.

\section{Kinematic parameters}

In addition to the dimensionless kinetic parameters, the variance of the dimensionless stride length $\left(\mathrm{SL}^{\mathrm{D}}\right)$ was studied.

The flexion extension angles at the ankle, the knee and the hip were also calculated and expressed in radian to respect the international unity system and the dimensionless form. In view of angle variability comparison, the averaged cycle was normalized to 100 points wherein each corresponded to a percentage of the cycle.

\subsection{Analysis to consider similarity}

The similarity analysis was a two step procedure, described in detail in the following paragraphs. Briefly, the first step was based on the correlation between the predicted subjectpaired scale factors (computed from basis scale factors) and the measured subject-paired scale factors (computed from measurements). The second step was to verify the variance decrease of the dimensionless parameters. Experimental setups that enable the increase of the scale factors' correlation and concomitantly decrease the variability will be considered as successful means to induce a dynamic similarity between different subjects.

A scale factor was a ratio of a mechanical parameter of one subject to another. With 19 subjects, 171 scale factors were built for each parameter. Basis scale factors $\left(C_{L}, C_{M}\right.$ and $\mathrm{C}_{\mathrm{T}}$ ) were derived from the three basis dimensions of any system (length, mass and time, respectively). $C_{L}$ was calculated by subject height ratios, predicted $C_{M}$ was computed from $\mathrm{C}_{\mathrm{M}}=\mathrm{C}_{\mathrm{L}}^{3}$ because the subjects had theoretically the same density index, and predicted $\mathrm{C}_{\mathrm{T}}$ 
depended on the experimental condition. Predicted scale factors were developed from the basis scale factors (Table 1) and represented how the individuals' parameters should be related if the conditions of dynamic similarity were met. Measured scale factors were those developed from the measurements of the mechanical parameters. For instance, the predicted scale factor between two subjects $S_{i}$ and $S_{j}$ for the braking peak was $\mathrm{C}_{\mathrm{BPF}}=\mathrm{C}_{\mathrm{FORCE}}=\mathrm{C}_{\mathrm{M}} \mathrm{C}_{\mathrm{L}} \mathrm{C}_{\mathrm{T}}^{-2}$ whereas the measured scale factor was $\mathrm{C}_{\mathrm{BPF}}=\mathrm{BPF}_{\mathrm{i}} / \mathrm{BPF}_{\mathrm{j}}$ with BPF the measured values. When for a given parameter all predicted scale factors equaled all measured scale factors, it could be stated that the parameter was similar or proportional from one subject to another. We reiterate that $\mathrm{C}_{\mathrm{L}}$ and $\mathrm{C}_{\mathrm{M}}\left(=\mathrm{C}_{\mathrm{L}}{ }^{3}\right)$ were given by anthropometry; however, predicted $\mathrm{C}_{\mathrm{T}}$ was dependent on experimental conditions and is presented hereafter.

$E C_{S P E E D}$

At the same speed, the speed scale factor (table 1) between subjects ( $i$ and $j$ ) was:

$C_{S P E E D}=\frac{v_{i}}{v_{j}}=C_{L} C_{T}^{-1}=1$, thus $\mathrm{C}_{\mathrm{T}}=\mathrm{C}_{\mathrm{L}}$ with $\mathrm{j} \in[1, \mathrm{n}]$ and $\mathrm{i} \neq \mathrm{j}$.

$E C_{N F R}$

The speed scale factor between two similar velocities $\left(\mathrm{C}_{\mathrm{L}} \mathrm{C}_{\mathrm{T}}^{-1}\right)$ was equal to $\mathrm{C}_{\mathrm{L}}^{0.5}$ (Eq. 7) that induced a $\mathrm{C}_{\mathrm{T}}=\mathrm{C}_{\mathrm{L}}{ }^{0.5}$ time scale factor.

$\frac{v \operatorname{sim}_{i}}{v \operatorname{sim} m_{j}}=\frac{\sqrt{\overline{N f r} g l_{i}}}{\sqrt{\overline{N f r} g l_{j}}}=\sqrt{\frac{l_{i}}{l_{j}}}=C_{L}^{0.5}$, thus $C_{T}=C_{L}^{0.5}$

$E C_{M O D}$

The frequency scale factor between two similar frequencies $\left(\mathrm{C}_{T}^{-1}\right)$ was equal to $\mathrm{C}_{\mathrm{L}}^{-0.5}$ (Eq. 8) that induced the time scale factor of $\mathrm{C}_{\mathrm{T}}=\mathrm{C}_{\mathrm{L}}{ }^{0.5}$.

$\frac{f \operatorname{sim}_{i}}{f \operatorname{sim}}=\frac{\overline{\operatorname{str}} v \operatorname{sim}_{i} / l_{i}}{\overline{\operatorname{str} v \operatorname{sim}} l_{j} / l_{j}}=\frac{v \operatorname{sim}_{i}}{v \operatorname{sim}_{j}} \frac{l_{j}}{l_{i}}=C_{L}^{0.5} C_{L}^{-1}=C_{L}^{-0.5}$, thus $C_{T}=C_{L}^{0.5}$ 
It should be noted that the variance decrease of dimensionless parameters signifies a more similar behavior [18].

\subsection{Statistical analysis}

All statistical analyses were performed with STATISTICA (STATISTICA V6, Statsoft, Maison-Alfort, FRANCE) and aimed to highlight which EC induce more similar behaviors, and more decrease of the inter-subject variability of the dimensionless parameters. Normality was checked using the Kolmogorov-Smirnov test. For normal distributions, parametric tests were performed else non parametric tests were used.

Statistical analysis performed on kinetic parameter scale factors was divided in two steps. First, a Spearman coefficient was computed between predicted and measured scale factors for each parameter in each speed stage under each experimental condition. Only significant correlations $(\mathrm{p}<0.05)$ were taken into account. Then, Wilcoxon paired tests were conducted to determine if there were significant differences between the predicted and the measured scale factors. If the Spearman correlation coefficient was significant and the Wilcoxon test did not reveal significant difference between predicted and measured scale factors for a kinetic parameter, then the parameter was considered as similar from one subject to another. The same tests were repeated on mass $\left(\mathrm{C}_{\mathrm{M}}\right)$ and step time $\left(\mathrm{C}_{\mathrm{T}}\right)$. Step time was defined from forceplate data as the time between heel strike and contralateral heel.

An ANOVA with 3 repeated factors ( $\mathrm{EC}_{\mathrm{SPEED}}, \mathrm{EC}_{\mathrm{NFR}}$ and $\left.\mathrm{EC}_{\mathrm{MOD}}\right)$ was conducted for ankle, knee and hip angles at each speed stage $(\mathrm{p}<0.05)$ to detect the significant effect of the experimental conditions on the inter-subject variance. A Tukey post hoc comparison allowed to refine the analysis. 
The homogeneity of variance of the dimensionless parameters between the three experimental conditions was tested with a Levene test $(\mathrm{p}<0.05)$. Then, the Fisher and Snedecor F-test $(\mathrm{p}<0.05)$ was performed as a post hoc test to highlight which variance was significantly different from the others. It was repeated for the six speed stages.

\section{Results}

For kinetic parameter scale factors, two criteria were taken into account to determine if one experimental condition produced more dynamic similarity than the others: first, the numbers of parameters for which the measured and predicted scale factors were correlated and non-statistically different from each other; then, the mean of the correlation value for these parameters. The dynamic similarity results are presented below and in Fig. 3. They were met for 11, 22 and 30 parameters out-of 36 dynamic parameters in $\mathrm{EC}_{\mathrm{SPEED}}, \mathrm{EC}_{\mathrm{NFR}}$ and $\mathrm{EC}_{\mathrm{MOD}}$, respectively. Similarity of $\mathrm{C}_{\mathrm{T}}$ was found only in $\mathrm{EC}_{\mathrm{MOD}}$. The mean coefficients of correlation for all parameters were $0.53,0.52$ and 0.69 in $\mathrm{EC}_{\mathrm{SPEED}}, \mathrm{EC}_{\mathrm{NFR}}$ and $\mathrm{EC}_{\mathrm{MOD}}$.

The standard deviations of ankle, knee and hip angles are presented in table 2 . The lowest variability of angles of ankle, knee and hip was met in $\mathrm{EC}_{\mathrm{NFR}}$ for the two first stages except for variability of the knee at the $0.56 \mathrm{~m} \cdot \mathrm{s}^{-1}$ speed. The lowest variability of angles of ankle, knee and hip was met in $\mathrm{EC}_{\mathrm{MOD}}$ for the other speeds. Moreover, $\mathrm{EC}_{\mathrm{NFR}}$ generated more variability of the three joint angles than the other conditions at these stages.

Referring to table 2, $\mathrm{EC}_{\mathrm{NFR}}$ allowed to reduce the variability of a total of 13 dimensionless parameters compared to $\mathrm{EC}_{\text {SPEED }}$. The variability of 30 dimensionless parameters decreased in $\mathrm{EC}_{\mathrm{MOD}}$ compared to $\mathrm{EC}_{\mathrm{SPEED}}$. $\mathrm{EC}_{\mathrm{MOD}}$ enabled to reduce the variability of 32 dimensionless parameters compared to $\mathrm{EC}_{\mathrm{NFR}}$. 
Throughout the three experimentation times, relations between Str and Nfr existed: $S t r=0.85 N f r^{-0.26} \quad\left(R^{2}=0.91\right), \quad S t r=0.91 N f r^{-0.25} \quad\left(R^{2}=0.94\right) \quad$ and $\quad S t r=$ $0.91 N f r^{-0.25}\left(R^{2}=1\right)$ in $\mathrm{EC}_{\mathrm{SPEED}}, \mathrm{EC}_{\mathrm{NFR}}$ and $\mathrm{EC}_{\mathrm{MOD}}$, respectively.

\section{Discussion}

The goal of this study was to ensure dynamic similarity between different-sized subjects using a new dimensionless number, Modela-w. As a combination of Nfr and Str, Nmodela-w accounts for the energy transfer at the CoM during walking.

The SMM was used to model CoM displacement in walking and to introduce Modelaw. The SMM behavior in single stance is defined by $7\left(\mathrm{~N}_{\mathrm{P}}=7\right)$ physical variables [19]: gravity $(\mathrm{g})$, mass $(\mathrm{m})$, stiffness $(\mathrm{k})$, initial spring length $\left(\mathrm{l}_{0}\right)$, initial spring angle $\left(\theta_{0}\right)$, initial landing velocity $\left(\mathrm{v}_{0}\right)$ and the angle of the initial landing velocity $\left(\beta_{0}\right)$. They depend on 3 $\left(\mathrm{N}_{\mathrm{D}}=3\right.$ ) base dimensions: length, mass and time. Applied to the SMM, the $\pi$ theorem [20] states that $\mathrm{N}_{P}-\mathrm{N}_{\mathrm{D}}=4$ dimensionless numbers are necessary to describe dynamic behaviors of the SMM. And, the relation $f\left(1_{0}, \mathrm{~m}, \mathrm{v}_{0}, \mathrm{k}, \mathrm{g}, \beta_{0}, \theta_{0}\right)=0$ can be reduced to that $\varphi\left(\pi_{1}, \pi_{2}, \pi_{3}, \pi_{4}\right)=0$; with $\pi_{1}, \pi_{2}, \pi_{3}$ and $\pi_{4}$ the associations $\left(\mathrm{l}_{0}{ }^{2} \mathrm{k} / \mathrm{mv}_{0}{ }^{2}=\mathrm{f}_{0}{ }^{2} 1_{0}^{2} / \mathrm{v}_{0}{ }^{2}\right)$, $\left(\mathrm{gl}_{0} / \mathrm{v}_{0}^{2}\right), \beta_{0}$ and $\theta_{0}$, respectively. $\pi_{1}$ and $\pi_{2}$ can be expressed as $\mathrm{Str}^{2}$ and $\mathrm{Nfr}^{-1}$. Thus, our approach focusing on energy fluctuation occurring at the CoM to ensure dynamic similarity by using Nfr and Str is in accordance with the $\pi$ theorem applied to the SMM.

Many studies compare mechanical parameters in a dimensionless form between different populations. This procedure normalizes the effect of the anthropometry, such as height and mass, on assessed parameters [18]. However, non similar conditions add an effect of experimental conditions on dimensionless parameters. For example, dimensionless parameters between an adult and a child both walking at $1 \mathrm{~m} \cdot \mathrm{s}^{-1}$ will be different and the differences should come from the non-similar experimental conditions. It means that similar 
conditions for different-sized subjects induce similar behaviors, and therefore the decrease of inter-subject variability of dimensionless parameters. In this study $\mathrm{Nfr}$ and $\mathrm{Str}$ have been proposed with the aim to more accurately study serious topics, such as ageing [21], development [22], gender [21,23] and obesity [24].

The increase of correlations between predicted and measured mechanical scale factors associated with the decrease of the dimensionless parameter variability underscore the interest of the association of $\mathrm{Nfr}$ and Str to induce dynamic similarity. In our study, $\mathrm{EC}_{\mathrm{MOD}}$ leads to more dynamic similarity than the other conditions. Our results show that the variability of mechanical dimensionless parameters decreases dramatically, close to zero, by imposing a Modela-w. Therefore, a dimensionless database could be built so as a set of dimensionless mechanical parameters would correspond to a Modela-w. Although the advantages of using database as reference have already been shown [21,25], a dimensionless database removes anthropometric individual characteristics on referenced parameters and would allow to i) compare species [26] and to ii) detect pathology among elderly [23] and young [27] by using deviation indexes [28]. Given that the dimensionless database would gather bio-markers of healthy walking (kinematic and dynamic), a relevant dimensionless deviation index could be proposed to detect a difference due to fitness, pathology, ageing, etc.

A recent study has highlighted a strong relationship between $\mathrm{Nfr}$ and $\mathrm{Str}$ among healthy subjects [29] $S t r=0.83 N f r^{-0.25}$. The relationship is very close in nature to that of the current study. This accordance suggests spontaneous Modela-w values corresponding to healthy behavior. It could thus be used as a tool to evaluate interventions or rehabilitation procedure.

Finally, the trajectory of the CoM in walking can be characterized by SMM and takes into account an elastic phenomenon, hence, the concomitant use of Nfr and Str according to Modela-w ensures dynamic similarity between different-sized subjects. This study highlights 
the importance of using similar experimental conditions by removing the effect of individual anthropometric characteristics to compare mechanical parameters. Modela-w is experimentally validated and further studies would show its usefulness in walking experimentation and clinical survey.

\section{Conflict of interest statement}

None.

\section{Acknowledgements}

None. 


\section{References}

[1] Alexander R. Optimization and Gaits in the Locomotion of Vertebrates. Physiol Rev 1989; 69(4): 1199-227.

[2] Delattre N, Lafortune MA, Moretto P. Dynamic similarity during human running: About Froude and Strouhal dimensionless numbers. J Biomech 2009; 42(3): 312-8.

[3] Moretto P, Bisiaux M, Lafortune MA. Froude number fractions to increase walking pattern dynamic similarities: Application to plantar pressure study in healthy subjects. Gait Posture 2007; 25(1): 40-8.

[4] Cavagna GA, Heglund NC, Taylor CR. Mechanical work in terrestrial locomotion: two basic mechanisms for minimizing energy expenditure. Am J Physiol 1977; 233(5): 243-61.

[5] Pandy MG. Simple and Complex Models for Studying Muscle Function in Walking. Philos Trans Biol Sci 2003; 358(1437): 1501-9.

[6] Lee CR, Farley CT. Determinants of the center of mass trajectory in human walking and running. J Exp Biol 1998; 201(21): 2935-44.

[7] Rummel J, Blum Y, Maus HM, Rode C, Seyfarth A. Stable and Robust Walking with Compliant Legs. Ieee International Conference on Robotics and Automation 2010: 5250-5.

[8] Cavagna GA, Saibene FP, Margaria R. Mechanical Work in Running. J Appl Physiol 1964; 19: 249-56.

[9] Delattre N, Moretto P. A new dimensionless number highlighted from mechanical energy exchange during running. J Biomech 2008; 41(13): 2895-8.

[10] De Leva P. Adjustments to Zatsiorsky-Seluyanov's segment inertia parameters. J Biomech 1996; 29(9): 1223-30.

[11] Ehrig RM, Taylor WR, Duda GN, Heller MO. A survey of formal methods for determining the centre of rotation of ball joints. J Biomech 2006; 39(15): 2798-809.

[12] Wu G, van der Helm FC, Veeger HE, Makhsous M, Van Roy P, Anglin C, Nagels J, Karduna AR, McQuade K, Wang XG, Werner FW, Buchholz B. ISB recommendation on definitions of joint coordinate systems of various joints for the reporting of human joint motion - Part II: shoulder, elbow, wrist and hand. J Biomech; 38(5): 981-92.

[13] Wu G, Siegler S, Allard P, Kirtley C, Leardini A, Rosenbaum D, Whittle M, D'Lima DD, Cristofolini L, Witte H, Schmid O, Stokes H. ISB recommendation on definitions of joint coordinate system of various joints for the reporting of human joint motion part 1: ankle, hip, and spine. J Biomech 2002; 35(4): 543-8.

[14] Hamill J, Mcniven S. Reliability of Selected Ground Reaction Force Parameters During Walking. Hum Mov Sci 1990; 9(2): 117-31.

[15] Goldberg SR, Stanhope SJ. Sensitivity of joint moments to changes in walking speed and body-weight-support are interdependent and vary across joints. J. Biomech 2013; 46(6): 1176-83.

[16] Verkerke GJ, Hof AL, Zijlstra W, Ament W, Rakhorst G. Determining the centre of pressure during walking and running using an instrumented treadmill. J Biomech 2005; 38(9): 1881-5.

[17] Villeger D, Costes A, Watier B, Moretto P. An algorithm to decompose ground reaction forces and moments from a single force platform in walking gait. Med Eng Phys 2014, http://dx.doi.org/10.1016/j.medengphy.2014.08.002

[18] Pierrynowski MR, Galea V. Enhancing the ability of gait analyses to differentiate between groups: scaling gait data to body size. Gait Posture 2001; 13(3): 193-201. 
[19] Blickhan R. The Spring Mass Model for Running and Hopping. J Biomech 1989; 22(11-12): 1217-27.

[20] Buckingham E. On physically similar systems. Illustration of the use of dimensional equations. Phys Rev 1914; 4: 345-76.

[21] Senden R, Grimm B, Heyligers IC, Savelberg HH, Meijer K. Acceleration-based gait test for healthy subjects: Reliability and reference data. Gait Posture 2009; 30(2): 192-6.

[22] Stansfield BW, Hillman SJ, Hazlewood ME, Robb JE. Regression analysis of gait parameters with speed in normal children walking at self-selected speeds. Gait Posture 2006; 23(3): 288-94.

[23] Hollman JH, McDade EM, Petersen RC. Normative spatiotemporal gait parameters in older adults. Gait Posture 2011; 34(1): 111-8.

[24] Silvernail JF, Milner CE, Thompson D, Zhang S, Zhao X. The influence of body mass index and velocity on knee biomechanics during walking. Gait Posture 2013; 37(4): 575-9.

[25] Lelas JL, Merriman GJ, Riley PO, Kerrigan DC. Predicting peak kinematic and kinetic parameters from gait speed. Gait Posture 2003; 17(2): 106-12, avr. 2003.

[26] Alexander R. Bipedal animals, and their differences from humans. J Anat 2004; 204(5): 321-30.

[27] Massaad A, Assi A, Skalli W, Ghanem I. Repeatability and validation of Gait Deviation Index in children: Typically developing and cerebral palsy. Gait Posture 2014; 39(1): 354-8.

[28] V. Cimolin V, M. Galli M. Summary measures for clinical gait analysis: A literature review. Gait Posture.

[29] Villeger D, Delattre N, Watier B, Moretto P. Froude and Strouhal dimensionless numbers to study human gait: an experimental approach. Comput Methods Biomech Biomed Engin 2012; 15 Suppl 1: 2012. 
Table 1

Units, dimensions and predicted scale factors of kinetic parameters

\begin{tabular}{|c|c|c|c|c|}
\hline \multirow{3}{*}{ Parameters } & Units & & Predicted & Dimensionless \\
\hline & \multicolumn{3}{|c|}{ Dimensions } & \multirow[b]{2}{*}{ parameters } \\
\hline & $(\mathrm{SI})$ & & scale factors & \\
\hline CoM height (I) & $\mathrm{m}$ & $\mathrm{L}$ & $C_{L}$ & \\
\hline Body mass (m) & $\mathrm{kg}$ & M & $C_{M}$ & \\
\hline Speed (v) & $\mathrm{m} \cdot \mathrm{s}^{-1}$ & $\mathrm{LT}^{-1}$ & $\mathrm{C}_{\mathrm{L}} \mathrm{C}_{\mathrm{T}}^{-1}$ & $\mathrm{Nfr}$ \\
\hline CoM oscillation frequency (f) & $s^{-1}$ & $\mathrm{~T}^{-1}$ & $\mathrm{C}_{\mathrm{T}}^{-1}$ & Str \\
\hline Time (TC and TPPF) & s & $\mathrm{T}$ & $\mathrm{C}_{\mathrm{T}}$ & Time $^{D}=$ Time $\times f$ \\
\hline Force (DPF and BPF) & $\mathrm{N}$ & $\mathrm{MLT}^{-2}$ & $C_{M} C_{L} C_{T}^{-2}$ & Force $^{D}=$ Force $/\left(\mathrm{mlf}^{2}\right)$ \\
\hline Impulse (VI, BI and PI) & N.S & $\mathrm{MLT}^{-1}$ & $C_{M} C_{L} C_{T}^{-1}$ & Impulse ${ }^{D}=$ Impulse $/$ (mgf) \\
\hline Rate (LR) & N.s ${ }^{-1}$ & $\mathrm{MLT}^{-3}$ & $\mathrm{C}_{\mathrm{M}} \mathrm{C}_{\mathrm{L}} \mathrm{C}_{\mathrm{T}}^{-3}$ & Rate $^{D}=$ Rate $/\left(\mathrm{mlf}^{3}\right)$ \\
\hline Length (SL) & $\mathrm{m}$ & $\mathrm{L}$ & $C_{L}$ & Length $^{\mathrm{D}}=$ Length / I \\
\hline Angle (Ankle, Knee and Hip) & Rad & & & Angle \\
\hline
\end{tabular}

$C_{L}$ and $C_{M}$ were defined by the subject's anthropometry whereas $C_{T}$ was determined by the experimental conditions. Abbreviations: TC time of contact, TPPF time to propulsive peak force, DPF damping peak force, BPF braking peak force, VI vertical impulse, BI braking impulse, PI propulsive impulse, LR loading rate and SL step length. 
Table 2

Standard deviation of dimensionless gait parameters at each speed stage

\begin{tabular}{|c|c|c|c|c|c|c|c|c|c|c|c|c|c|}
\hline $\begin{array}{l}\text { Mean } \\
\text { walking } \\
\text { speed } \\
\text { stage }\end{array}$ & EC & $\begin{array}{l}\text { Ankle } \\
\text { angle } \\
\left(\times 10^{3}\right)\end{array}$ & $\begin{array}{l}\text { Knee } \\
\text { angle } \\
\left(\times 10^{3}\right)\end{array}$ & $\begin{array}{l}\text { Hip } \\
\text { angle } \\
\left(x 10^{3}\right)\end{array}$ & $\mathrm{SL}^{\mathrm{D}}$ & $\mathrm{TC}^{\mathrm{D}}$ & $\mathrm{TPPF}^{\mathrm{D}}$ & $\mathrm{DPF}^{\mathrm{D}}$ & $\mathrm{BPF}^{\mathrm{D}}$ & $\mathrm{VI}^{\mathrm{D}}$ & $\mathrm{Bl}^{\mathrm{D}}$ & $\mathrm{PI}^{\mathrm{D}}$ & $\mathrm{LR}^{\mathrm{D}}$ \\
\hline \multirow{3}{*}{$\begin{array}{l}0.56 \\
m . s^{-1}\end{array}$} & $\mathrm{EC}_{\text {SPEED }}$ & 2.1 & 2.8 & 1.4 & 0.11 & 0.33 & 0.27 & 0.20 & 0.01 & 0.35 & 0.01 & 0.01 & 0.37 \\
\hline & $\mathrm{EC}_{\mathrm{NFR}}$ & $1.7 *$ & 2.7 & 1.4 & 0.10 & 0.28 & 0.22 & 0.19 & 0.01 & 0.46 & 0.01 & 0.01 & 0.42 \\
\hline & $\mathrm{EC}_{\mathrm{MOD}}$ & $2.0 * \#$ & $2.5^{* \#}$ & $1.5^{* \#}$ & $0.00 * \#$ & $0.06 *^{* \#}$ & $0.04^{* \#}$ & $0.04^{* \#}$ & 0.01 & $0.11^{* \#}$ & 0.01 & $0.01^{\#}$ & 0.31 \\
\hline \multirow{3}{*}{$\begin{array}{l}1.11 \\
m . s^{-1}\end{array}$} & $\mathrm{EC}_{\text {SPEED }}$ & 2.3 & 2.4 & 1.3 & 0.11 & 0.18 & 0.14 & 0.16 & 0.02 & 0.15 & 0.01 & 0.01 & 0.69 \\
\hline & $E C_{N F R}$ & $1.7 *$ & $2.1 *$ & $1.2 *$ & $0.06^{*}$ & 0.14 & 0.11 & 0.17 & 0.03 & 0.18 & 0.01 & 0.01 & 0.77 \\
\hline & $\mathrm{EC}_{\mathrm{MOD}}$ & $2.3^{\#}$ & $2.2^{* \#}$ & $1.3^{\#}$ & $0.00 * \#$ & $0.03^{* \#}$ & $0.02 * \#$ & $0.06{ }^{* \#}$ & $0.02^{\#}$ & $0.07^{* \#}$ & 0.01 & 0.01 & $0.37^{* \#}$ \\
\hline \multirow{3}{*}{$\begin{array}{l}1.67 \\
m . s^{-1}\end{array}$} & $\mathrm{EC}_{\text {SPEED }}$ & 2.7 & 2.7 & 1.5 & 0.12 & 0.14 & 0.12 & 0.13 & 0.05 & 0.10 & 0.01 & 0.01 & 1.18 \\
\hline & $\mathrm{EC}_{\mathrm{NFR}}$ & $2.6^{*}$ & $2.9 *$ & $1.6^{*}$ & $0.06^{*}$ & 0.13 & 0.11 & 0.14 & 0.05 & 0.12 & 0.02 & 0.02 & 1.17 \\
\hline & $\mathrm{EC}_{\mathrm{MOD}}$ & $2.5^{* \#}$ & $2.5^{* \#}$ & $1.5^{\#}$ & $0.00 * \#$ & $0.03^{* \#}$ & $0.02 * \#$ & $0.08^{* \#}$ & $0.03^{\#}$ & $0.05^{* \#}$ & 0.01 & 0.01 & $0.28^{* \#}$ \\
\hline \multirow{3}{*}{$\begin{array}{l}2.22 \\
m . s^{-1}\end{array}$} & $\mathrm{EC}_{\text {SPEED }}$ & 2.8 & 3.0 & 1.8 & 0.17 & 0.14 & 0.12 & 0.18 & 0.06 & 0.10 & 0.02 & 0.02 & 1.18 \\
\hline & $\mathrm{EC}_{\mathrm{NFR}}$ & $3.0 *$ & $3.2^{*}$ & $2.0 *$ & $0.08 *$ & 0.10 & 0.08 & 0.17 & 0.05 & 0.12 & 0.02 & 0.02 & 1.26 \\
\hline & $E_{M O D}$ & $2.6{ }^{* \#}$ & $2.7^{* \#}$ & $1.8^{* \#}$ & $0.00 * \#$ & $0.04^{* \#}$ & $0.03^{* \#}$ & 0.14 & 0.04 & $0.05^{* \#}$ & 0.01 & 0.01 & $0.48^{* \#}$ \\
\hline
\end{tabular}

The characteristic dimensions to express the gait parameters in a dimensionless form $\left({ }^{\mathrm{D}}\right)$ are: the mass $([\mathrm{M}])$, the CoM height $([\mathrm{L}])$ and the step frequency $\left(\left[\mathrm{T}^{-1}\right]\right)$.

*, " : variability significantly different from $\mathrm{EC}_{\mathrm{SET}}$ and from $\mathrm{EC}_{\mathrm{NFR}}$. The significant lowest values of standard deviation are bolded.

Abbreviations : SL stride length, TC time of contact, TPPF time to propulsive peak force, DPF damping peak force, BPF braking peak force, VI vertical impulse, BI braking impulse, PI propulsive impulse and LR loading rate. 


\section{Figure legends}

Figure 1. Relationship between velocity, frequency and CoM height in the three experimental conditions for each speed stage.

Figure 2. (A) Vertical reaction force (Fz) over time. 1: Time of Contact (TC); 2: Damping Peak Force (DPF); 3: Loading Rate from $10 \%$ to $90 \%$ of vertical peak force (LR); 4: Vertical Impulse (VI). (B) Antero-posterior reaction force (Fy) over time. 1: Braking Peak Force (BPF); 2: Time to Propulsive Peak Force (TPPF); 3: Braking Impulse (BI); 4: Propulsion Impulse (PI).

Figure 3. Correlations between predicted and measured scale factors of body mass $\left(\mathrm{C}_{\mathrm{M}}\right)$, step time $\left(\mathrm{C}_{\mathrm{T}}\right)$ and kinetic parameters (TC, time of contact; TPPF, time to propulsive peak force; DPF, damping peak force; BPF, braking peak force; VI, vertical impulse; BI, braking impulse; PI, propulsive impulse; and LR, loading rate). The scale factor correlation whose the Wilcoxon test revealed a difference between predicted and measured scale factors was set to 0. Lightest grey, dark grey and black bars represent respectively dynamic similarity for $\mathrm{EC}_{\mathrm{SPEED}}, \mathrm{EC}_{\mathrm{NFR}}$ and $\mathrm{EC}_{\mathrm{MOD}}$. 


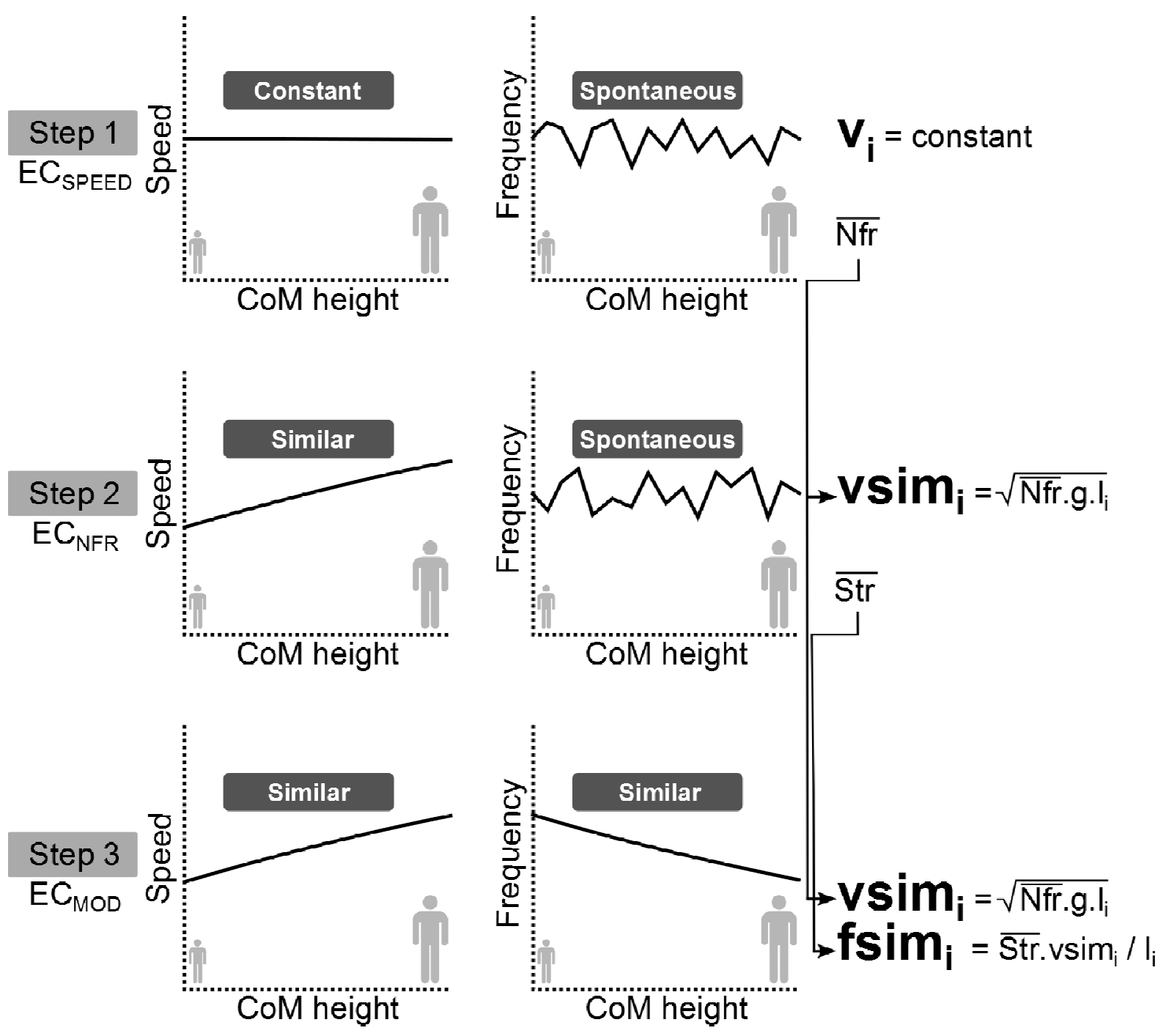

Fig. 1 
Fig. 2
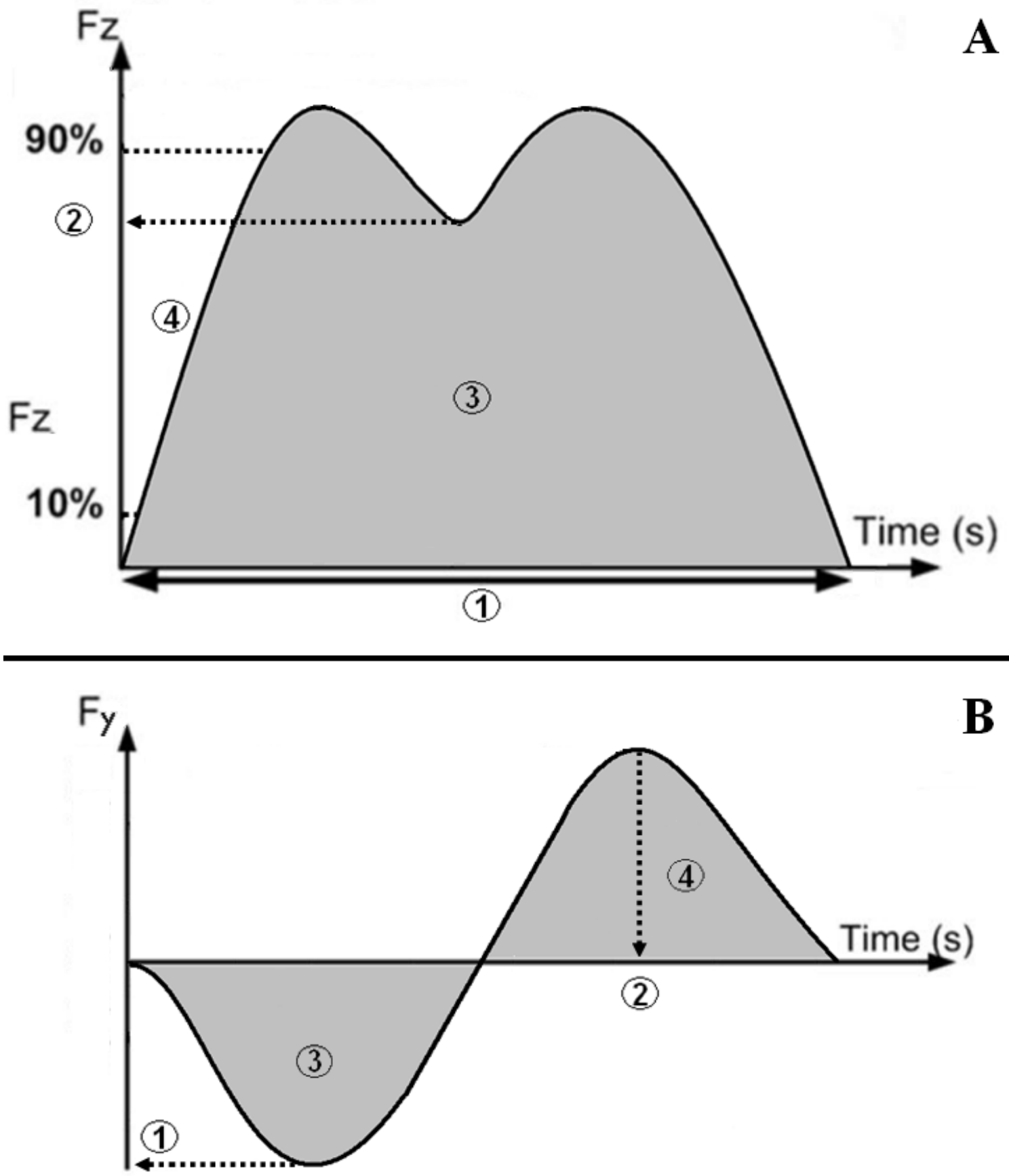

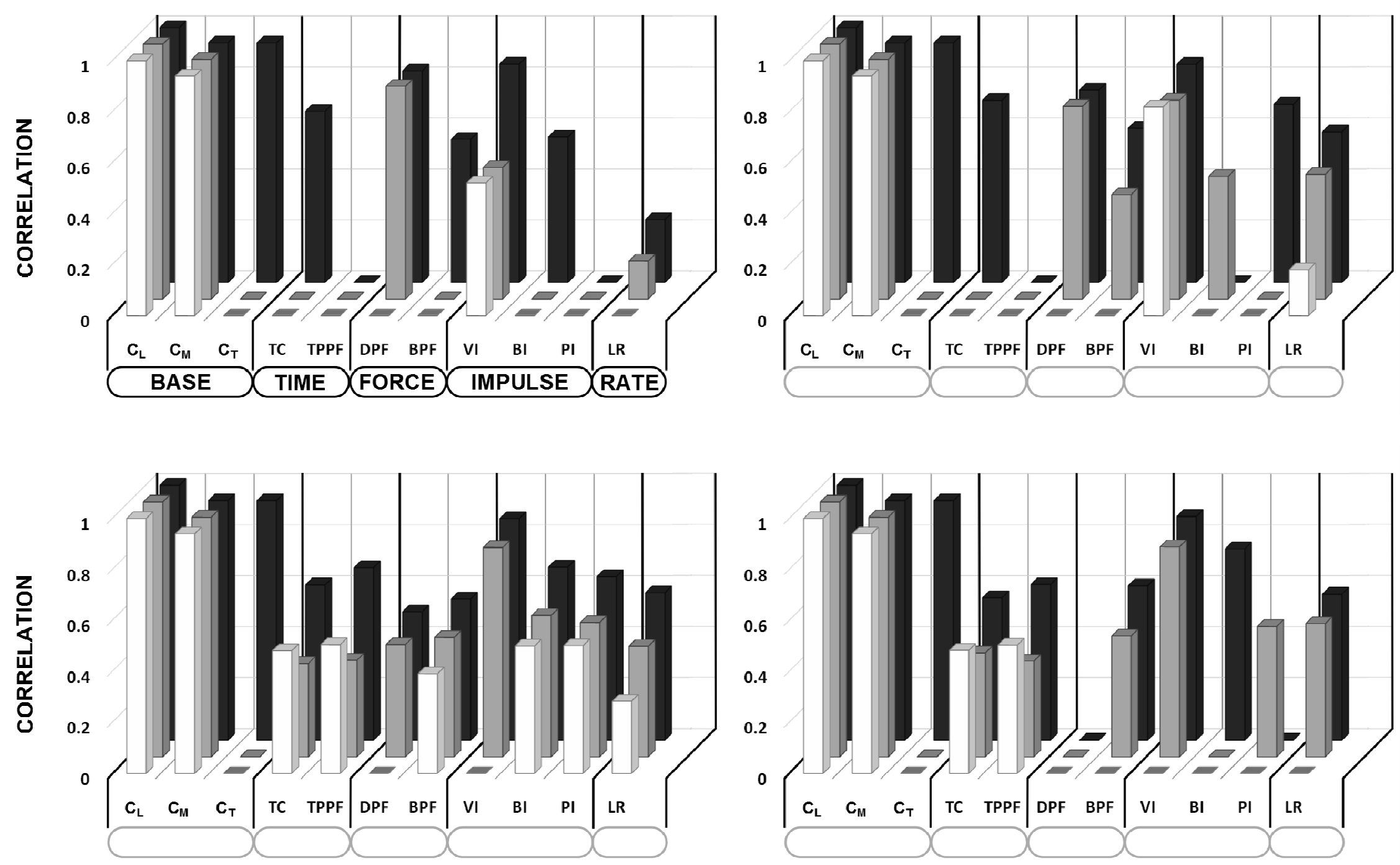

Fig. 3 